\title{
An Examination of the Relationship Between Strength and Speed in Elementary School Students
}

\author{
Yasin Arslan $^{1} \&$ Serdar Aktan ${ }^{2}$ \\ ${ }^{1}$ School of Physical Education and Sport, Gaziosmanpaşa University, Turkey \\ ${ }^{2}$ Milli Eğitim Bakanlığı, Turkey \\ Correspondence: Yasin Arslan, School of Physical Education and Sport, Gaziosmanpaşa University, Turkey. \\ E-mail: arslan@gazi.edu.tr
}

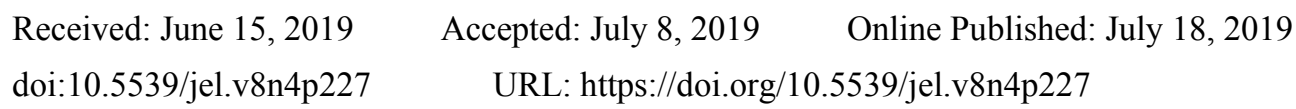

\begin{abstract}
This study intends to examine the relationship between strength and speed in Cumhuriyet Elementary School in Samsun. The study group consists of 240 students (120 boys and 120 girls) aged 11-14 years who participated voluntarily in the study through random selection.

This study investigated the relationship among the values of leg and back strength, 30-second sit-up, standing long jump, vertical jump, reaction time, and $10 \mathrm{~m}$ and $20 \mathrm{~m}$ sprint running of 5 th through 8 th graders.

Intragroup strength and speed relationships of each class and gender were examined separately in the study. Data were analyzed through Pearson product-moment correlation coefficient in SPSS package program with a .05 margin of error $(\mathrm{p}<.05)$.

As a result of the study, it was observed that the strength and speed increased in conjunction with the age variable and there was a significant negative correlation between $10 \mathrm{~m}$ and $20 \mathrm{~m}$ sprint running and strength values. That is, the sprint running time decreased as the strength increased. According to the results obtained in the study, it was seen that there was a significant relationship between strength and speed in school children aged 11-14 years and that speed and strength performances affected each other. However, no significant linear relationship was found between reaction time and strength.
\end{abstract}

Keywords: elementary school students, strength, speed

\section{Introduction}

The concept of strength in sports sciences was defined and found meaning in different ways. Strength is usually defined as the ability to withstand resistance or the ability to bear resistance to some extent (Sevim, 2007; Akgün, 1994). On the other hand, Uniformity of views as far as the comprehension of the definition of "human strength" has long existed in sport science the term is understood as the ability to overcome resistance or to oppose it at the cost of muscle tension (Trzaskoma, 2001). The factors affecting the formation of strength are classified as physiological, coordinative, morphological (structural) and psychodynamic (Muratl1,1997).

In sports, speed means that people apply their motoric actions in the shortest period of time and in the most intense way. The factors affecting speed are heredity, reaction time, the ability to overcome external resistances, technique, concentration and will muscle flexibility. Speed characteristics are used in different sports branches in a structure specific to the branch. It is a prerequisite that it is applied in a short time and that fatigue occurs. In this respect, the internal and external structural features of the branches must be close to each other in order to use speed in different branches (Bompa, 1998).

The relationship between strength and speed, the relationship among muscular development, calendar age and testosterone secretion are considered among the factors affecting the course of sprint running across age (Dirix et al., 1988). One of the important factors affecting muscle performance is the ability to contract rapidly and strongly at the same time. Rapid and strong contraction is a feature needed in all sports branches. Strong and rapid contraction is related to the ratio of fast twitch fibers present in muscles. The relationship between strength and speed varies depending on the very high number of FT fibrils found in muscles. It is known that athletes with high FT fibril rates will be faster (Fox, 1988). 
The timing of muscle contraction is important for movements that require large amounts of strength. The improvement in the ability to initiate and coordinate the contraction of the muscles involved in the movement during the first week of the training program is seen as an important factor. Therefore, speed-specific adaptations can be explained by learning the skills of training programs and reflecting the development of such activations at the speed of training (Almasbakk \& Hoff, 1996).

In the school age (11-14 years), the reaction rate reaches almost that of adults. The movement speed increases continuously. During this period, starts with acoustic signals, sudden starts while jogging, starts from various basic stands, incremental runs, jogs, and $30 \mathrm{~m}-50 \mathrm{~m}$ sprint running are activities aimed at improving speed (Muratl1, 1997).

Conducted with a large group of students aged 11-14 in a middle school of Ministry of National Education (MEB), this study aims to reveal the significance of studies determining the values of strength and speed in children aged 11-14 thus contribute to both the selection of athletes and training programs for physical education teachers and coaches. As a result, the data obtained can be compared to the level of similar characteristics of people of the same age who do not yet exercise at the same time.

\section{Method}

\subsection{Study Group}

The study group comprises a total number of 240 students (120 boys and 120 girls) studying in Cumhuriyet Elementary School in Bafra District of Samsun Province who voluntarily participated and were randomly selected. The relationship among the values of leg and back strength, 30-second sit-up, standing long jump, vertical jump, reaction time, and $10 \mathrm{~m}$ and $20 \mathrm{~m}$ sprint running of 5 th through 8 th graders was examined in this study.

The measurements were carried out in the sports hall of Bafra Cumhuriyet Elementary School with the tools obtained from the laboratories of the Ondokuz Mayıs University Yaşar Doğu School of Physical Education and Sports. All measurements were completed within 4 weeks. While their height was being measured, the subjects were resting on a metal rod which was fixed on the precision scales and the body was completely upright and the jaw was kept parallel to the ground. All values obtained were recorded in centimeter $(\mathrm{cm})$. Body weights were measured with digital 'Tefal'-brand scale with a sensitivity of 0.01 kilogram $(\mathrm{kg})$. During the measurements, it was ensured that the subjects were weighed with bare feet and wearing only shorts and T-shirts, and all the values obtained were recorded in $\mathrm{kg}$.

\subsection{Data Collection}

\subsubsection{Vertical Jump Test}

In the measurements, a waist-mounted jump meter with a sensitivity of $1 \mathrm{~cm}$ between $5 \mathrm{~cm}$ and $99 \mathrm{~cm}$ was used. In the normal upright position, the subjects were allowed to jump upward with maximum force after a rapid downward movement with hands-free. The application was repeated twice, with the best value recorded in $\mathrm{cm}$.

\subsubsection{Standing Long Jump Test}

In the gymnasium, the subjects whose fingertips of both feet were pressed on the line drawn on the parquet floor jumped as far forward as possible from their position. Measurements were taken between the line and the part of the body that touched the ground closest to the line and the application was repeated twice. The best value was recorded in $\mathrm{cm}$.

\subsubsection{Speed Tests}

For the measurement, a stopwatch with a 0.001 second sensitivity and two photocell-operated electric circuits with reflector and start/stop functions were used. The photocell which starts the time was placed at the starting point and the photocell circuits that stop the time were placed at the distances of $10 \mathrm{~m}-20 \mathrm{~m}$. The height of the photocells from the ground was set to $1 \mathrm{~m}$ and the subjects were told what to do during the run. The subjects started the run with the 'Start' command in the standing start position and were allowed to complete the run without changing direction. $10 \mathrm{~m}$ and $20 \mathrm{~m}$ speed tests were applied to 240 subjects separately. The test was applied to the subjects twice, and the best running times were recorded.

\subsubsection{Sit-Up Test}

A mat and a stopwatch were used in the test. The feet of the subjects were held still and it was ensured that their knee angle was 90 degrees. The attempts they made within 30 seconds were recorded. 


\subsubsection{Reaction Time Measurement Test}

The subject placed the index finger on the button of the device and waited for the light warning on the device and a warning signal was given within three seconds after the 'ready' command. The stopwatch started to operate as soon as the light warning was given. As soon as the subject noticed the light warning and pressed the button, the stopwatch stopped and the time was recorded. The first five attempts were counted as trials and the mean of the last five attempts were recorded.

\subsection{Data Analysis}

The data obtained from the study were analyzed using SPSS (Windows 22.0). Pearson product-moment analysis was used to investigate whether there was a relationship between the variables and was analyzed with 0.05 error margin.

\section{Findings}

Table 1. Mean values of boy students

\begin{tabular}{|c|c|c|c|c|c|c|c|c|}
\hline \multirow[t]{2}{*}{ Parameters } & \multicolumn{2}{|c|}{ 5th grade $(N=20)$} & \multicolumn{2}{|c|}{6 th grade $(N=20)$} & \multicolumn{2}{|c|}{7 th grade $(N=20)$} & \multicolumn{2}{|c|}{ 8th grade $(\mathrm{N}=20)$} \\
\hline & $\overline{\mathrm{x}}$ & ss & $\overline{\mathrm{x}}$ & Ss & $\overline{\mathrm{x}}$ & ss & $\overline{\mathrm{x}}$ & ss \\
\hline Height (cm) & 145.08 & 7.31 & 149.41 & 4.40 & 156.48 & 7.15 & 158.93 & 6.94 \\
\hline Weight (kg) & 42.1 & 9.92 & 40.44 & 4.27 & 47.71 & 7.31 & 47.87 & 7.66 \\
\hline Age (year) & 11 & 0.00 & 12 & .00 & 13 & .00 & 14 & .00 \\
\hline $10 \mathrm{~m}$. Speed Test (sec) & 2.38 & 0.22 & 2.08 & .12 & 2.13 & .13 & 2.05 & .11 \\
\hline $20 \mathrm{~m}$. Speed Test (sec) & 4.28 & 0.31 & 3.78 & .29 & 3.84 & .32 & 3.67 & .28 \\
\hline Vertical Jump (cm) & 30.1 & 3.52 & 41.55 & 6.00 & 45.65 & 5.05 & 41.55 & 4.11 \\
\hline Standing Long Jump (cm) & 125.5 & 17.92 & 148.50 & 14.13 & 156.60 & 10.29 & 159.60 & 13.85 \\
\hline 30-second Sit-Up (rep) & 21.3 & 3.46 & 21.50 & 3.96 & 21.60 & 2.92 & 21.35 & 2.60 \\
\hline Reaction Time (ms) & 0.204 & 5.104 & .199 & 4.839 & .197 & 5.791 & .193 & 6.148 \\
\hline
\end{tabular}

Table 2. Mean values of girl students

\begin{tabular}{lllllllll}
\hline \multirow{2}{*}{ Parameters } & \multicolumn{3}{c}{ 5th grade $(\mathbf{N}=\mathbf{2 0})$} & \multicolumn{2}{l}{ 6th grade $\mathbf{( N = 2 0 )}$} & \multicolumn{2}{l}{ 7th grade $(\mathbf{N}=\mathbf{2 0})$} & \multicolumn{2}{l}{ 8th grade $(\mathbf{N}=\mathbf{2 0})$} \\
\cline { 2 - 10 } & $\overline{\mathrm{x}}$ & $\mathrm{ss}$ & $\overline{\mathrm{x}}$ & $\mathrm{ss}$ & $\overline{\mathrm{x}}$ & $\mathrm{ss}$ & $\overline{\mathrm{x}}$ & $\mathrm{ss}$ \\
\hline Height (cm) & 145.21 & 5.49 & 148.65 & 5.35 & 156.25 & 6.16 & 157.37 & 4.49 \\
Weight (kg) & 39.70 & 7.06 & 38.52 & 6.18 & 50.57 & 10.60 & 50.53 & 9.17 \\
Age (year) & 11 & .00 & 12 & .00 & 13 & .00 & 14 & .00 \\
10 m. Speed Run (sec) & 2.45 & .14 & 2.31 & .13 & 2.28 & .18 & 2.33 & .11 \\
20 m. Speed Run (sec) & 4.44 & .31 & 4.13 & .20 & 4.13 & .36 & 4.17 & .22 \\
Vertical Jump (cm) & 26.95 & 3.30 & 34.85 & 4.34 & 36.10 & 5.34 & 36.30 & 5.11 \\
Standing Long Jump (cm) & 121.80 & 12.12 & 136.40 & 13.26 & 138.30 & 21.97 & 147.30 & 13.58 \\
30-second Sit-Up (rep) & 18.20 & 3.83 & 18.10 & 2.90 & 18.95 & 2.85 & 18.55 & 2.52 \\
Reaction Time (ms) & .207 & 6.159 & .204 & 5.943 & .198 & 6.270 & .194 & 5.963 \\
\hline
\end{tabular}

Table 3. Strength-speed correlation values of 11-year-old boys

\begin{tabular}{lllll}
\hline & & Vertical Jump (cm) & Standing Long Jump (cm) & 30-Second-Sit-Up (rep) \\
\hline $\mathbf{1 0}$ m Speed Run (sec) & P. Correlation (r) & -.426 & -.409 & -.369 \\
& Significance & .061 & .073 & .109 \\
& N & 20 & 20 & 20 \\
\multirow{2}{*}{$\mathbf{2 0}$ m Speed Run (sec) } & P. Correlation & -.676 & -.611 & -.716 \\
& Significance & $\mathbf{. 0 0 1}^{*}$ & $\mathbf{. 0 0 4}^{*}$ & $\mathbf{. 0 0 0}^{*}$ \\
& N & 20 & 20 & 20 \\
Reaction Time (ms) & P. Correlation & .3 .48 & .217 & .297 \\
& Significance & .132 & .358 & .212 \\
& N & 20 & 20 & 20 \\
\hline
\end{tabular}

Note. ${ }^{*}=\mathrm{p}<.05$.

When Table 3 is examined, it is seen that there was a negative correlation between $20 \mathrm{~m}$ running times and vertical jump, standing long jump and 30 -second sit-up test values $(\mathrm{p}<.05)$. While the sit-up, vertical jump and long jump values increased, the running times of $20 \mathrm{~m}$ distance shortened. It was seen that there was no 
significant relationship between strength and speed test results.

Table 4. Strength-speed correlation values of 12-year-old boys

\begin{tabular}{lllll}
\hline & & Vertical Jump (cm) & Standing Long Jump (cm) & 30-Second-Sit-Up (rep) \\
\hline \multirow{20}{*}{ m Speed Run (sec) } & P. Correlation (r) & -.209 & -.322 & -.848 \\
& Significance & .377 & .166 & $\mathbf{. 0 0 0}^{*}$ \\
& N & 20 & 20 & 20 \\
\multirow{2}{*}{$\mathbf{2 0}$ m Speed Run (sec) } & P. Correlation (r) & -.181 & -.363 & -.835 \\
& Significance & .445 & .115 & $\mathbf{. 0 0 0}^{*}$ \\
& N & 20 & 20 & 20 \\
Reaction Time (ms) & P. Correlation (r) & .083 & .294 & -.558 \\
& Significance & .729 & .208 & $\mathbf{. 0 1 1 *}$ \\
& N & 20 & 20 & 20 \\
\hline
\end{tabular}

Note. ${ }^{*}=\mathrm{p}<.05$.

When Table 4 is examined, a significant negative relationship was found between shuttle and $10 \mathrm{~m}$ speed run, 20 $\mathrm{m}$ speed run and reaction time $(\mathrm{p}<.05)$, but no significant correlation was found between strength and speed test results.

Table 5. Strength-speed correlation values of 13-year-old boys

\begin{tabular}{lllll}
\hline & & Vertical Jump (cm) & Standing Long Jump (cm) & 30-Second-Sit-Up (rep) \\
\hline \multirow{20}{*}{$\mathbf{m}$ Speed Run (sec) } & P. Correlation (r) & .158 & -.061 & -.421 \\
& Significance & .507 & .799 & .065 \\
& N & 20 & 20 & 20 \\
\multirow{2}{*}{$\mathbf{2 0}$ m Speed Run (sec) } & P. Correlation (r) & -.030 & -.003 & -.556 \\
& Significance & .899 & .991 & $\mathbf{. 0 1 1 *}$ \\
& N & 20 & 20 & 20 \\
Reaction Time (ms) & P. Correlation (r) & -.006 & .108 & .458 \\
& Significance & .978 & .650 & $\mathbf{. 0 4 2}$ \\
& N & 20 & 20 & 20 \\
\hline
\end{tabular}

Note. ${ }^{*}=\mathrm{p}<.05$.

When Table 5 is examined, it is seen that there was a significant negative relationship between the 30 -second sit-up and 20-meter speed runs and a significant positive relationship between sit-up and reaction time $(\mathrm{p}<.05)$. There was no significant relationship between strength and speed test results.

Table 6. Strength-speed correlation values of 14-year-old boys

\begin{tabular}{lllll}
\hline & & Vertical Jump (cm) & Standing Long Jump (cm) & 30-Second-Sit-Up (rep) \\
\hline $\mathbf{1 0}$ m Speed Run (Sec) & P. Correlation (r) & -.504 & -.689 & -.756 \\
& Significance & $\mathbf{. 0 2 4 *}$ & $\mathbf{. 0 0 1 *}$ & $\mathbf{. 0 0 0 *}$ \\
& N & 20 & 20 & 20 \\
\multirow{2}{*}{$\mathbf{2 0}$ m Speed Run (sec) } & P. Correlation (r) & -.409 & -.638 & -.679 \\
& Significance & .074 & $\mathbf{. 0 0 2}$ & $\mathbf{. 0 0 1 *}$ \\
& N & 20 & 20 & 20 \\
Reaction Time (ms) & P. Correlation (r) & .044 & .314 & .050 \\
& Significance & .853 & .178 & .835 \\
& N & 20 & 20 & 20 \\
\hline
\end{tabular}

Note. ${ }^{*}=\mathrm{p}<.05$.

There was a significant negative correlation between $10 \mathrm{~m}$ speed run and all three forces $(\mathrm{p}<.05)$, while $20 \mathrm{~m}$ speed run was negatively correlated with standing long jump and sit-up test values (Table 6). 
Table 7. Strength-speed correlation values of 11-year-old girls

\begin{tabular}{lllll}
\hline & & Vertical Jump (cm) & Standing Long Jump (cm) & 30-Second-Sit-Up (rep) \\
\hline \multirow{10}{*}{ m Speed Run (sec) } & P. Correlation (r) & -.097 & -.273 & -.314 \\
& Significance & .685 & .244 & .178 \\
& N & 20 & 20 & 20 \\
\multirow{2}{*}{20 m Speed Run (sec) } & P. Correlation (r) & -.157 & -.228 & -.615 \\
& Significance & .508 & .334 & $\mathbf{. 0 0 4 *}$ \\
& N & 20 & 20 & 20 \\
Reaction Time (ms) & P. Correlation (r) & .019 & -.423 & -.091 \\
& Significance & .936 & .063 & .704 \\
& N & 20 & 20 & 20 \\
\hline
\end{tabular}

Note. ${ }^{*}=\mathrm{p}<.05$.

In Table 7, it is seen that there was a significant negative relationship between $20 \mathrm{~m}$ speed run and sit-up test values only in 11 -year-old girls $(\mathrm{p}<.05)$.

Table 8. Strength-speed correlation values of 12-year-old girls

\begin{tabular}{lllll}
\hline & & Vertical Jump (cm) & Standing Long Jump (cm) & 30-Second-Sit-Up (rep) \\
\hline \multirow{10}{*}{ m Speed Run (sec) } & P. Correlation (r) & -.492 & -.596 & -.676 \\
& Significance & $.028^{*}$ & $.006^{*}$ & $.001^{*}$ \\
& N & 20 & 20 & 20 \\
\multirow{2}{*}{$\mathbf{2 0}$ m Speed Run (sec) } & P. Correlation (r) & -.349 & -.621 & --793 \\
& Significance & .132 & $\mathbf{. 0 0 3 *}$ & $\mathbf{. 0 0 0 *}$ \\
& N & 20 & 20 & 20 \\
Reaction Time (ms) & P. Correlation (r) & .274 & .162 & .191 \\
& Significance & .242 & .494 & .420 \\
& N & 20 & 20 & 20 \\
\hline
\end{tabular}

Note. ${ }^{*}=\mathrm{p}<.05$.

It is observed in Table 8 that there was a significant negative relationship between $20 \mathrm{~m}$ speed run and sit-up test values in 12-year-old girls just as in 11 -year-old girls $(\mathrm{p}<.05)$.

Table 9. Strength-speed correlation values of 13-year-old girls

\begin{tabular}{lllll}
\hline & & Vertical Jump (cm) & Standing Long Jump (cm) & 30-Second-Sit-Up (rep) \\
\hline $\mathbf{1 0}$ m Speed Run (sec) & P. Correlation (r) & -.532 & -.414 & -.249 \\
& Significance & $\mathbf{. 0 1 6 ^ { * }}$ & .070 & .290 \\
& $\mathrm{~N}$ & 20 & 20 & 20 \\
\multirow{2}{*}{$\mathbf{2 0}$ m Speed Run (sec) } & P. Correlation (r) & -.552 & -.491 & -.427 \\
& Significance & $\mathbf{. 0 1 2 ^ { * }}$ & $\mathbf{. 0 2 8}$ & .060 \\
& N & 20 & 20 & 20 \\
Reaction Time (ms) & P. Correlation (r) & -.168 & .066 & .087 \\
& Significance & .479 & .781 & .716 \\
& N & 20 & 20 & 20 \\
\hline
\end{tabular}

Note. ${ }^{*}=\mathrm{p}<.05$.

When Table 9 is examined, there was a significant negative relationship among $10 \mathrm{~m}$ speed run and vertical jump, $20 \mathrm{~m}$ speed run and vertical jump, and standing long jump $(\mathrm{p}<.05)$. 
Table 10. Strength-speed correlation values of 14-year-old girls

\begin{tabular}{lllll}
\hline & & Vertical Jump (cm) & Standing Long Jump (cm) & 30-Second-Sit-Up (rep) \\
\hline \multirow{20}{*}{$\mathbf{m}$ Speed Run (sec) } & P. Correlation (r) & -.122 & -.073 & -.504 \\
& Significance & .608 & .760 & $\mathbf{. 0 2 3}^{*}$ \\
& $\mathrm{~N}$ & 20 & 20 & 20 \\
\multirow{2}{*}{$\mathbf{2 0}$ m Speed Run (sec) } & P. Correlation (r) & -.097 & -.011 & -.562 \\
& Significance & .685 & .965 & $\mathbf{. 0 1 0 ^ { * }}$ \\
& N & 20 & 20 & 20 \\
\multirow{2}{*}{ Reaction Time (ms) } & P. Correlation (r) & -.041 & .162 & -.084 \\
& Significance & .862 & .496 & .725 \\
& N & 20 & 20 & 20 \\
\hline
\end{tabular}

Note. ${ }^{*}=\mathrm{p}<.05$.

Table 10 shows that there was a significant negative relationship among $10 \mathrm{~m}$ speed run, $20 \mathrm{~m}$ speed run and 30 -second-sit-up $(\mathrm{p}<.05)$.

\section{Discussion and Conclusion}

In this study which aimed to examine the relationship between strength and speed of elementary school students, the mean value of vertical jump of boy students with a mean age of $11,12,13$ and 14 respectively was $30.10 \pm$ $3.52 \mathrm{~cm}, 41.55 \pm 6.00 \mathrm{~cm}, 36.10 \pm 5.34 \mathrm{~cm}, 41.55 \pm 4.11 \mathrm{~cm}$, while it was $26.95 \pm 3.30 \mathrm{~cm}, 34.85 \pm 4.34 \mathrm{~cm}, 36.10$ $\pm 5.34 \mathrm{~cm}, 36.30 \pm 5.11 \mathrm{~cm}$ for the girl students of the same age groups. It should be noted that the month differences of children at these ages play an important role in the values obtained. In a study by Babel et al. (2005), the effect of pre-adolescent boys' sprint running performance on some parameters was investigated and the average vertical jump value of children with an average age of 11.49 was found to be $33.94 \mathrm{~cm}$.

In the study conducted by Çoknaz (2002) examining the physical education courses in primary education curriculum and the physical development of the students in Bolu and Cologne, the mean scores of 30-second sit-up values of the boy students aged 11-14 in Bolu were 16.44 for 11-year-olds, 16.82 for 12-year-olds, 18.13 for 13-year-olds, 19.53 for 14-year-olds while they were 13.50 for 11-year-olds, 11.82 for 12-year-olds, 12.56 for 13-year-olds, and 11.29 for 14-year-olds in girl students. The mean scores of 30-second sit-up values of boy students in Cologne were 18.71 for 11-year-olds, 18.56 for 12-year-olds, 22.08 for 13-year-olds, and 18.75 for 14-year-olds while they were 13.44 for 11 -year-olds, 16.33 for 12 -year-olds, 15.83 for 12-year-olds, and 14.63 for 14-year-olds in girl students.

In this study, the mean scores of 30-second sit-up values of boy students were 21.30 for 11-year-olds, 21.50 for 12-year-olds, 21.60 for 13-year-olds, and 21.35 for 14-year-olds while they were 18.20 for 11-year-olds, 18.10 for 12-year-olds, 18.95 for 13-year-olds, and 18.55 for 14-year-olds in girl students. It can be said that the difference seen between these two studies was due to the age of months of students known to be quite effective at these ages.

In Uzuncan's study (1991) on the aerobic strength and physical fitness of boy students aged 11-12 with Eurofit tests, the values in standing long jump for those who do sports were $147.75 \mathrm{~cm}$ for 11 -year-olds and $160.24 \mathrm{~cm}$ for 12 -year-olds while they were $146.23 \mathrm{~cm}$ for 11 -year-olds and $141.00 \mathrm{~cm}$ for 12 -year-olds in those who do not do sports. This study revealed that the values of standing long jump in 11 -year-old boys were $121.23 \mathrm{~cm}$ and $136.40 \mathrm{~cm}$ in 12-year-olds. This shows that the values of the study group were lower than those found by Uzuncan (1991). The behaviors of adolescent children vary within themselves. This difference may have been reflected in the performance of children. The specificity of the age of 12 is the fact that the structure of motor abilities (precisely-strength) undergoes significant changes. Decreased is the number of tight relationships between every parameter characterising strength capacities - whereas the autonomy of the development of the functions of the organism increases. The increase of speed and strength abilities proceeds in an uneven way. The highest increment is observed between the ages 12-13, during the first stages of training activities. During this period, the increment of results of the standing high jump is $14.09 \%$. In the period between the ages 13 and 14 it still rises by $8.52 \%$. At ages of $14-15$ - the rate of increments rises again by $-9.23 \%$. In the following years the rate of increments is subject to a decrease. The lowest increment occurs between the ages 15-16 (3.77\%) (Jagiello et al., 2004). Late or early puberty may also have affected the performance of children. The growth process should be taken into consideration when evaluating physical performance in children and adolescents (Kale \& Kara, 1998). Early adolescent individuals have more muscular development and are physically stronger than non-adolescents (Dusek, 1987). It was also found that the increase in testosterone secretion accelerated from 10-11 to 15 years (Dirix et al., 1988). However, it can be said that the month differences in the ages of the 
children in the other studies and in this study played a major role in the differentiation of their results. Sonkin and Zajcewa ascertain that the biggest increments of speed and strength abilities in young people occur between the ages $12-13$, that is at the end of the puberty leap in their development.

In the study, no significant relationship was found between reaction time and strength. It is known that reaction time, attention, concentration, and simple visual reaction time were variably affected by age, vocabulary, dexterity and solvent exposure (Agnew et al., 1991). On the other hand, it was stated that there might be changes in reaction time due to increased anxiety. These changes may show less alteration in individuals who learn a coping technique or experience more stress (Schmidth, 1991).

Genetic factors influence the speed of strentgh and flexibility. In people with different muscle structures, strength development will also be different because the size of the muscle mass and the fibril type are known to influence the development of strength (Ağaoğlu, 1994). Accelerating from a stationary position or a moving start requires high force generation capacity to overcome the body's inertia. Thus, training techniques involving a high external resistance are useful for developing acceleration (Ebben, 2001). The teachers, however, lack the competence to design programs for developing complex psychomotor fitness. Identification of effects attainable with the use of an expanded physical education program containing mainly athletic training but based on the existing 3-hour-a-week schedule, on developing essential motor fitness of first-grade school children is thus highly important (Katic, 1994).

This study concluded that strength and speed showed an increase with age (11-14) and there was a significant negative correlation among $10 \mathrm{~m}$ and $20 \mathrm{~m}$ sprint running and strength. In other words, sprint running time decreased as strength increased. According to the findings of this study, it was seen that there was a significant relationship between strength and speed in 11-14 years old school children and that speed and strength performances affected each other.

\section{References}

Agaoglu, S. A. (1994). The selection of talent in 11-15-year-old wrestlers in turkey. Marmara University Institute of Health Sciences Department of Physical Education and Sports, İstanbul.

Agnew, J., Schwartz, B. S., Bella, K. 1., Ford, D. P., \& Blecker, M. L. (1991). Comparison of computerized and examiner-administered neurobehavioral testing techniques. $J$ Occup Med., 33(11). https://doi.org/10.1097/00043764-199111000-00012

Almåsbakk, B., \& Hoff, J. (1996). Coordination, the determinant of velocity specificity? Journal of Applied Physiology, 81(5), 2046-2052. https://doi.org/10.1152/jappl.1996.81.5.2046

Babel, K., Hertogh, C., \& Hue, O. (2005). Influence of ethnic origin on predictive parameters of performance in sprint running in prepubertal boys. International Journal of Sports Medicine, 26(09), 798-802. https://doi.org/10.1055/s-2004-830562

Bompa, T. O. (1998). Training Theory and Method. Ankara: Bağırgan Publishing.

Çoknaz, H. (2002). Investigation of Physical Development of Students with Physical Education Courses in Primary Education Programs. Doctoral Dissertation, Samsun.

Dirix, A., Knuttgen, H. G., \& Tittel, K. (Eds.). (1991). The Olympic book of sports medicine, 1. Oryx/Greenwood.

Dusek, B. J. (1987). Adolecent Development and Behavior. USA: Prentice - Hall International.

Ebben, W. P., \& Blackard, D. O. (2001). Strength and conditioning practices of National Football League strength and conditioning coaches. The Journal of Strength \& Conditioning Research, 15(1), 48-58. https://doi.org/10.1519/00124278-200102000-00009

Fox, E, L. (1988). Sports Physiology. USA: Saunders College Publishing.

Jagiełło, W., Kalina, R. M., \& Tkaczuk, W. (2004). Development of strength abilities in children and youths. Biol Sport, 21(4), 351-368.

Kale, R., \& Kara, E. (1998). Sports, Culture and Modern Industrial World. 5th International Congress of Sport Sciences, Ankara.

Katić, R., Zagorac, N., Živičnjak, M., \& Hraski, Ž. (1994). Taxonomic analysis of morphological/motor characteristics in seven-year old girls. Collegium Antropologicum, 18(1), 141-154.

Muratlı, S. (1997). Children and Sports. Ankara: Bağırgan Publishing. 
Schmidt, R. A. (1991). Motor Learning and Performance: From Principles to Practice (Champaign). IL. Illinois: Human Kinetics Books.

Sevim, Y. (2007). Knowledge of Training. Nobel Publication Distribution.

Sonkin, W. D., \& Zajcewa, W. W. (1990). Wozrastnaja dynamika fiziczieskich wozmożnostiej szkolnikow (bioenergeticzieskij aspiekt). Tjeor.Prakt.Fiz.Kult., 9, 38-44.

Uzuncan, H. (1991). Measurement of Aerobic Strength and Physical Fitness of Male Students between 10-12 Years with Eurofit Tests. MA Thesis, Konya.

Trzaskoma, Z., \& Trzaskoma, Ł. (2001). The proportion between maximal torque of core muscles in male and female athletes. Acta Bioeng Biomech, 3(Suppl 2), 601-606.

\section{Copyrights}

Copyright for this article is retained by the author, with first publication rights granted to the journal.

This is an open-access article distributed under the terms and conditions of the Creative Commons Attribution license (http://creativecommons.org/licenses/by/4.0/). 